\title{
Brafv600e and Ctbn1 Mutational Study in Rathke's Cleft Cysts
}

\author{
Antonelli $\mathbf{M}^{1^{*}}$, Badiali $\mathbf{M}^{2}$, Moi $\mathrm{L}^{2}$, Arcella $\mathbf{A}^{3}$, Buttarelli $\mathrm{FR}^{4}$, Minasi $\mathbf{S}^{5}$ and Giangaspero $\mathrm{F}^{1,3}$ \\ ${ }^{1}$ Department of Radiological, Oncological and Anatomo-Pathological Sciences, Sapienza University of Rome, Rome, Italy \\ ${ }^{2}$ Bone Marrow Transplantation Unit, Microcitemico Children's Hospital, Via Jenner s/n 09121, Cagliari, Italy \\ 3IRCCS Neuromed, 86077 Pozzilli (IS), Italy \\ ${ }^{4}$ Department of Neurological Sciences, Sapienza University, Rome, Italy \\ ${ }^{5}$ Department of Molecular Medicine, Sapienza University, Rome, Italy
}

"Corresponding author: Manila Antonelli, Department of Radiological, Oncological and Anatomo-Pathological Sciences, Sapienza University of Rome, Viale Regina Elena 324, Rome, 00161, Italy, Tel: +396 4468606; Fax: +39649979175; E-mail: manila.antonelli@uniroma1.it

Received date: August 02, 2016; Accepted date: September 02, 2016; Published date: September 05, 2016

Copyright: ( 2016 Antonelli M, et al. This is an open-access article distributed under the terms of the Creative Commons Attribution License, which permits unrestricted use, distribution, and reproduction in any medium, provided the original author and source are credited.

\begin{abstract}
Aim: Rathke's cleft cysts and craniopharyngiomas tipically involve sellar region and their histogenetic relationship is still matter of debate. Clinical and histopathologic differentiation of cystic lesions from the sellar region, that is, craniopharyngiomas (CPs) and Rathke cleft cysts (RCCs), is challenging and has great importance with respect to variable clinical manifestation and adapted surgical treatment strategies in both entities. The recent acquisition that adamantinomatous and papillary craniopharyngiomas bear distinct molecular alterations i.e., $\beta$-catenin (CTNNB1) and BRAFv600 mutations respectively, has suggest to screen for such alteration a series of Rathke cyst to seek a possible relation with one of the two craniopharyngioma type.
\end{abstract}

Methods: Seven Rathke's cleft cysts were analyzed for BRAF and CTNNB1 mutational status by sequencing and immunohistochemistry. Radiological, clinical and histological features were performed.

Results: None of the 7 Rathke's cleft cysts harbor BRAFV600E mutation. No CTNNB1 mutation was found. Radiological, clinical and histological re-evaluation of the cases confirmed the diagnosis of Rathke's cleft cysts.

Conclusion: BRAFV600E and CTNNB1 mutations appeared, as most reliable factor for the differentiation between purely cystic CPs and RCCs, whereas tumor location, tumor size, and radiological parameter of the tumor were less consistent parameters. This study again confirms that craniopharyngiomas (CPs) and Rathke cleft cysts (RCCs), are associated with distinct pathogenic pathways.

Keywords: BRAFV600E mutation; Rathke's cleft cysts; Craniopharyngioma; Sequencing

\section{Introduction}

Rathke's cleft cyst (RCC) and craniopharyngiomas (CP) involve the cellar region and sometimes histological evaluation is challenging especially when small tissue specimens are available for analysis. Both lesions are considered to arise from the remnants of Rathke's diverticulum [1].

Some authors have suggested that these lesions are part of a disease spectrum extending from RCC to craniopharyngioma [2]. Intracystic hemorrhage or inflammation may induce metaplasia in the single cuboidal epithelium of RCC to form stratified squamous epithelia resulting in the induction of craniopharyngioma [3]. Besides the presence of ciliated and goblet cell in some craniopharyngiomas are believed to provide evidence for this [4,5]. Moreover most of the CPs are larger than $20 \mathrm{~mm}$, whereas most of RCCs are smaller than $20 \mathrm{~mm}$ in diameter. However, these parameters are insufficient to rule out small cystic CP variants, which do not exhibit any other difference in computed tomography (CT), or magnetic resonance imaging (MRI) [6].
Although CPs and RCCs are histologically benign, they exhibit a different clinical behavior and thus require different surgical treatment strategies. The rates of recurrence and progression, respectively and the interval of progression-free survival in CPs is obviously depending on the extent of surgical removal [7]. The recurrence rate is significantly lower in patients with RCC even after subtotal or partial removal [7]. The outcome is much better and one might conclude from previous data that radical excision is not necessary in these lesions. On the basis of these data distinction between the lesions is truly important. However, the small tissue specimens available for analysis and the similar histological features cause a tricky interpretation.

Previous work has shown that mutations in CTNNB1 with nuclear accumulation of $\beta$-catenin are a reliable marker for the identification of craniopharyngiomas of the adamantinomatous subtype [5f]. Whereas papillary craniopharyngiomas are characterized by BRAF V600E mutations as genetic hallmark and consistently don't show nuclear $\beta$-catenin expression [8].

On the basis of these data we investigated 7 Rathke's cleft cysts to determine the presence of BRAF V600E and beta-catenin mutations and its suitability as diagnostic marker for the differentiation of cystic lesions of the cellar region. For each case clinical, radiological and 
Page 2 of 4

histopathological parameters were also re-evaluated in order to exclude features typical for craniopharyingoma.

\section{Materials and Methods}

\section{Patient selection and immunohistochemistry}

Surgical specimens from 7 patients with Rathke's cleft cysts were selected retrospectively on the basis of the availability of formalin-fixed paraffin embedded material (FFPE) from two different institutions, the Mediterranean Neurologic Institute (Neuromed), Pozzilli, Italy, and the Pathology Service of University Sapienza, Rome, Italy.

All Rathke's cleft cysts were reviewed by two neuropathologist MA and FG and diagnosed according to the AFIP Atlas of Tumor Pathology (Tumors of the Central Nervous System, Series 4 Fascicle 7).

Primary antibody against BRAF p.Val600Glu (clone VE1, 1:100, Spring Bioscience, Pleasanton, CA): positive staining was characterized by diffuse and moderate cytoplasmic staining of the tumor cells.

Primary antibody against $\beta$-catenin antigen (BD Pharmingen, 610154, mouse monoclonal, clone 14): were scored as positive, and cases with membranous staining were scored as negative.

\section{Isolation of DNA}

DNA was extracted from FFPE tissue specimens with the QIAamp DNA Mini Kit, as described by the manufacturer (Qiagen S.A., Courtaboeuf France), DNA concentration was quantified using the Nanodrop ND-1000 UV-Vis spectrophotometer (Labtech France, Palaiseau, France). Final products were stored at $-20^{\circ} \mathrm{C}$ until use.

Moreover standard diagnostic procedures were performed. Sections were stained with ematoxilin and eosin.

\section{BRAFV600E and CTNNB1 mutation analysis}

Mutational analysis was performed amplifying DNA with the primers as follows: BRAF exon 15, 5'TCATAATGCTTGCTCTGATAGGA-3' (sense) and 5'-GGC CAAAAATTTAATCAGTGGA-3' (antisense). The PCR products were purified using the automated system Biomek NXp by Beckman Coulter and Agentcourt AMPure XP reagents. Purified products were submitted to PCR cycle sequencing conditions as follow: denaturation at $95^{\circ} \mathrm{C}$ for $30 \mathrm{~s}$, annealing at $50^{\circ} \mathrm{C}$ for $15 \mathrm{~s}$, and extention at $60^{\circ} \mathrm{C}$ for $240 \mathrm{~s}$. The cycle sequencing products were purified using the same automated system and Agentcourt Clean SEQ reagents. Sequencing analysis was performed using the ABI 3130 XL DNA analyser (Applied Biosystem).

For $\beta$-catenin, a 630 base pair genomic PCR fragment spanning codon 1 (exon 2) to codon 92 (exon 4) was amplied using primers primers BCATEX2F (GAAAATCCAGCGTGGACAATG) and BCATEX4R (TCGAGTCATTGCA- TACTGTCC).

\section{Results}

\section{Clinical, histological and radiological findings}

The series of 7 Rathke's cleft cysts comprised 7 females and 1 male, with a median age of 38. Cases were located within the sella turcica except for one located in the sphenoidal bone (Table 1).

\begin{tabular}{|c|c|c|c|c|}
\hline Case & $\begin{array}{l}\text { Age } \\
\text { (years)/ } \\
\text { Sex }\end{array}$ & RCC histology & $\begin{array}{l}\text { BRAFV600 } \\
\text { E mutation }\end{array}$ & $\begin{array}{l}\text { B- } \\
\text { catenin } \\
\text { mutatio } \\
\text { n }\end{array}$ \\
\hline 1 & $56 \mathrm{~F}$ & $\begin{array}{l}\text { Ciliated cuboidal and columnar } \\
\text { epithelium with squamous } \\
\text { metaplasia }\end{array}$ & No & No \\
\hline $2^{*}$ & $16 \mathrm{~F}$ & $\begin{array}{l}\text { Ciliated cuboidal and columnar } \\
\text { epithelium }\end{array}$ & No & No \\
\hline 3 & $55 \mathrm{~F}$ & $\begin{array}{l}\text { Ciliated cuboidal and columnar } \\
\text { epithelium }\end{array}$ & No & No \\
\hline 4 & $33 \mathrm{~F}$ & $\begin{array}{l}\text { Ciliated cuboidal and columnar } \\
\text { epithelium }\end{array}$ & No & No \\
\hline 5 & $48 \mathrm{~F}$ & $\begin{array}{l}\text { Ciliated cuboidal and columnar } \\
\text { epithelium with squamous } \\
\text { metaplasia }\end{array}$ & No & No \\
\hline 6 & $29 \mathrm{~F}$ & $\begin{array}{l}\text { Ciliated cuboidal and columnar } \\
\text { epithelium }\end{array}$ & No & No \\
\hline 7 & $32 \mathrm{M}$ & $\begin{array}{l}\text { Ciliated cuboidal and columnar } \\
\text { epithelium }\end{array}$ & No & No \\
\hline
\end{tabular}

Table 1: RCC histology and mutations in different cases.

We further added two cases of craniopharingiomas, one papillary and one adamantinomatous, in which the histological and radiological features were typical. The histological examination showed cuboidal or columnar ciliated epithelium on a fibrous tissue. In three of 7 Rathke cleft cysts (n.1 n.2 n.5) co-existence of squamous cell metaplasia and cilia with scattered goblet cells could be identified. The intrasphenoidal case (n.2) showed columnar cilated epithelium with few mucinous cells (Figure 1).

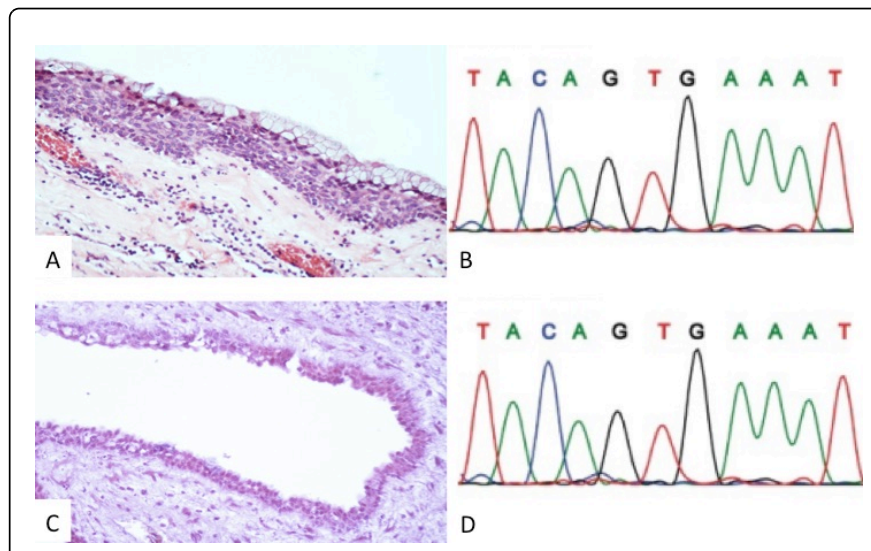

Figure 1: Case 1 A) Haematoxylin and eosin staining show coexistence of squamous cell metaplasia and cilia with scattered goblet cells; B) BRAFV600E sequencing demonstrate the wild type gene. Case 2 C) Haematoxylin and eosin staining show show cuboidal or columnar ciliated epithelium on a fibrous tissue; D) BRAFV600E sequencing demonstrate the wild type gene.

Radiological re-evaluation in all seven cases demonstrated the typical MR finding of a Rathke's cleft cyst such as dumbell-shaped cyst, with hypointense signal in T1-weighted images, and hyperintense signal in T2-weighted images, relative to normal brain parenchyma 
Page 3 of 4

and they were smaller than $20 \mathrm{~mm}$ in diameter. Moreover in three of 7 Rathke cleft cysts (n.1 n.2 n.5) and the intrasphenoidal lesion (n.2) MRI showed findings typical of a cystic lesion.

All reported cases achieve remission, except for a single patient that developed repeated re-accumulation of the mucus and become intractable (Figure 1).

\section{BRAFV600E and $\beta$-catenin mutational status by immunohistochemistry}

Immunoistochemical for BRAFV600E protein was found negative in all RCCs, as well the cases did not show nuclear expression for $\mathrm{B}$ catenin. To confirm the quality of the immunohistochemistry, we found positive cells for CTNB1 and BRAFV600E in respectively one adamantinomatous craniopharingioma and one papillary craniofaringioma (Figure 2).

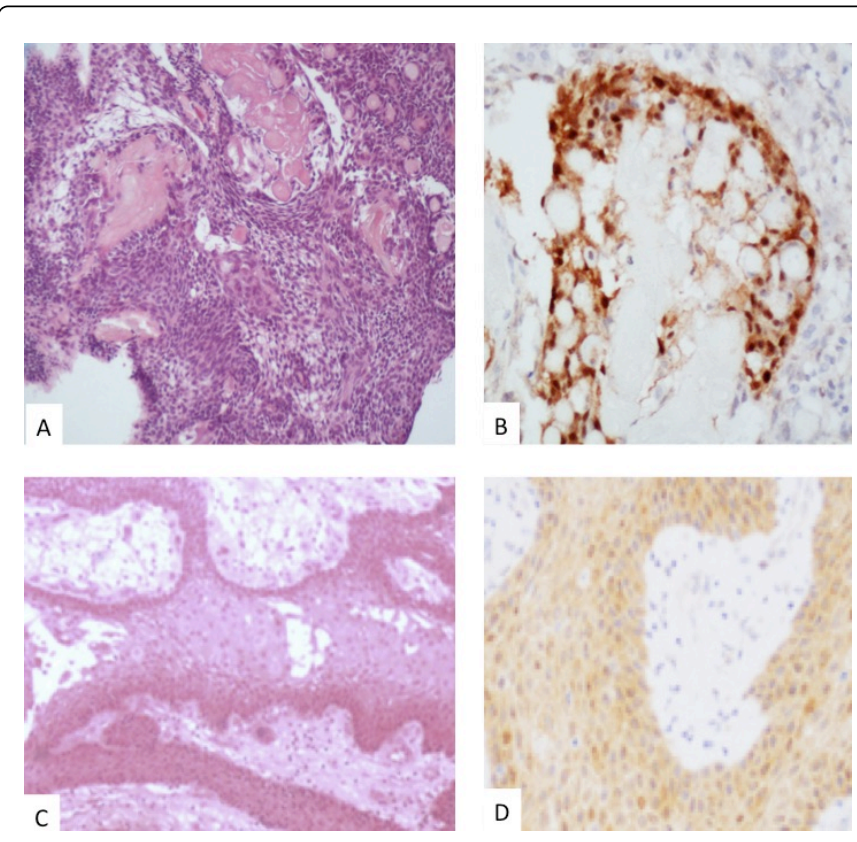

Figure 2: A) Adamantinomatous craniopharingioma with typically stratified epithelium and palisading arrangement of the basal cells. Flat cells within a loose stroma are also evident (hematoxylin and eosin $[\mathrm{H} \& \mathrm{E}]$ stain) B) $\beta$-catenin is localized to the cytoplasm and the nucleus in an adamantinomatous craniopharyngioma. C) Papillary craniopharingioma is formed of mature squamous epithelium without surface maturation. Focal tissue dehiscence with resultant pseudopapillary architecture is present (hematoxylin and eosin [H\&E] stain). D) positive staining for BRAFV600E was characterized by diffuse and moderate cytoplasmic staining of the tumor cells.

\section{BRAFV600E and CTNNB1 ( $\beta$-catenin) mutation analysis}

We additionally performed sequencing in all cases. None of the seven RCC, showed mutations in BRAF (Figure 1) and CTNNB1 (Bcatenin).

\section{Discussion}

Rathke's cleft cysts and craniopharyngiomas typically arise in the sellar region and on histological examination by some authors they are considered part of a disease spectrum [2].

Histological evidence are shown by Park, et al. [4] which described the occurrence of a primary tumor with microscopic features of RCC, followed by a progression diagnosed as aCP with nuclear accumulation of beta-catenin, arguing for the possibility that CPs may develop from RCCs directly due to beta-catenin mutations.

Moreover other cases of RCC with smooth transitions from single cuboidal epithelium to squamous and/or stratified epithelium in Rathke's epithelia and ciliated and goblet cell craniopharyngioma are believed to provide evidence for this spectrum $[5,8]$.

Moreover, in practice, purely cystic CPs is extremely difficult to distinguish from RCCs during preoperative analysis and by microscopical evaluation. Nevertheless, differentiating both entities is important because the operative management and follow-up is different. One major factor is the risk of persisting endocrine deficits after extensive resection of $\mathrm{CP}$ masses that can be avoided in less aggressive partial resection of the RCC wall.

The recent acquisition that adamantinomatous and papillary craniopharyngiomas harbour distinct molecular alterations i.e., $\beta$ catenin (CTNB1) [5] and BRAFv600 mutations [8] respectively stimulate us to screen a series of seven cases of RCC for both mutations using immunohistochemistry and DNA sequencing. Moreover we re-evaluated clinical, radiological and histopathological parameters.

Radiological re-evaluation in all seven cases demonstrated a dumbbell-shaped cyst, with hypointense signal in T1-weighted images, and hyperintense signal in T2-weighted images, relative to normal brain parenchyma. The diameter of all cases was smaller than $20 \mathrm{~mm}$. Moreover in three of 7 Rathke cleft cysts and the intrasphenoidal lesion MRI showed findings typical of a cystic lesion, causing a challenge in differential diagnosis with CP.

The histological parameters of the cases showed columnar mucinproducing, ciliated cells with a focal area of squamous epithelium. The intrasphenoidal case showed columnar epithelial layer with cilia and rare goblet cells: the peculiarity of the latter case was the unusual location in the sphenoidal bone, which although rare, one case has been reported [9].

All cases were negative for BRAFV600E and CTNB1 mutations. On the other hand the two craniopharingioma adamantinomatous and papillary tested showed respectively BRAFV600E and CTNB1 immunopositivity. Published series of RCC do not harbour the BRAF V600E mutation [10] except for a recent paper by Schweizer, et al. [11] in which they analysed for BRAF status 33 RCC, and found 3 cases harbouring BRAFV600E mutation. The authors performed immunohistochemistry in all cases and pyrosequencing in 8 out 33 . Pyrosequencing results of the VE1 positive cases clearly indicated the presence of a BRAF V600E mutation whereas in one case a low level mutation was observed.

The histological re-evaluation of the three positive cases showed unusual morphological features for RCC and also clinical parameters were unusual especially the adult ages of patients that were typically of RCC. This re-evaluation prompt the authors to re-diagnosed the BRAF positive case as papillary craniopharyngiomas. The paper by Schweizer, 
et al. focuses on the importance of a careful histological evaluation of cystic sellar lesion for an accurate distinction between RCC with squamous metaplasia and papillary craniopharyngioma.

Our study was carried out in a series similar to those of Schweizer, et al. with respect to number of sequenced cases. However, the histological and radiological re-evaluation of the two BRAFv600E mutated RCC cases confirmed that they were misdiagnosed papillary craniopharyngioma, being composed ofesions showed a collagenous cyst wall layered by flat squamous epithelium mixed with columnar cells with cilia and goblet cells. Moreover the clinical parameters were consistent with this diagnosis such as the young age of the case to allow us to exclude a craniopharyngioma rare in young. Also MRI showed features consistent with the diagnosis of RCC such as a dumbellshaped cyst, with hypointense signal in $\mathrm{T} 1$ and hyperintense signal in T2-weighted images.

In conclusion the issue of a possible spectrum between papillary craniopharyngiomas and Rathke's cleft cysts, as supposed by others, was not supported in our study, both on histological and genetic level. Finally, in extensively cystic CP, difficult to differentiate from RCC, the pathological evaluation associated with molecular findings could definitively define the diagnosis.

\section{Acknowledgement}

Manila Antonelli was supported by a grant from the "Fondazione Italiana per la Lotta al Neuroblastoma".

\section{References}

1. Burger PC, Scheithauer BW (1994) Tumors of the Central Nervous System; Washington DC: Armed Forces Institute of Pathology pp. 357-359.
2. Wolfe SQ, Heros RC (2010) A Rathke cleft cyst to craniopharyngioma: is there a spectrum? J Neurosurg 112:1322-1333.

3. Zada G, Lin N, Ojerholm BSE, Ramkissoon S, Laws ER (2010) Craniopharyngioma and other cystic epithelial lesions of the sellarregion: a review of clinical, imaging, and histopathological relationships. Neurosurg Focus 28: E4.

4. Park YS, Ahn JY, Kim DS, Kim TS, Kim SH (2009) Late development of craniopharyngioma following surgery for Rathke's cleft cyst. Clin Neuropathol 28: 177-181.

5. Hofmann BM, Kreutzer J, Saeger W, Buchfelder M, Blümcke I, et al. (2006) Nuclear beta-catenin accumulation as reliable marker for the differentiation between cystic craniopharyngiomas and rathke cleft cysts: a clinico-pathologic approach. Am J Surg Pathol 30: 1595-1603.

6. Shin JL, Asa SL, Woodhouse LJ, Smyth HS, Ezzat S (1999) Cystic lesions of the pituitary: clinicopathological features distinguishing craniopharyngioma, Rathke's cleft cyst, and arachnoid cyst. J Clin Endocrinol Metab 84: 3972-3982.

7. Shirane R, Su CC, Kusaka Y, Jokura H, Yoshimoto T (2002) Surgical outcomes in 31 patients with craniopharyngiomas extending outside the suprasellar cistern: an evaluation of the frontobasal interhemispheric approach. J Neurosurg 96: 704-712.

8. Brastianos PK, Taylor-Weiner A, Manley PE, Jones RT, Dias-Santagata D, et al. (2014) Exome sequencing identifies BRAF mutations in papillary craniopharyngiomas. Nat Genet 46: 161-165.

9. Megdiche-Bazarbacha H, Hammouda BK, Aicha AB, Sebai R, Belghith L, et al. (2006) Intrasphenoidal rathke cleft cyst. AJNR Am J Neuroradiol 27: 1098-1100.

10. Jones RT, Abedalthagafi MS, Brahmandam M, Greenfield EA, Hoang MP, et al. (2014) Cross-reactivity of the BRAF VE1 antibody with epitopes in axonemal dyneins leads to staining of cilia. Mod Pathol 28: 596-606.

11. Schweizer L, Capper D, Hölsken A, Fahlbusch R, Flitsch J, et al. (2014) BRAF V600E analysis for the differentiation of papillary Craniopharyngiomas and Rathke's Cleft Cysts. Neuropathol Appl Neurobiol 41: 733-742. 